\title{
The Exploration of the Training Mode in the Major of Information Security in University
}

\author{
Zuli Wang*, Luqiao Zhang and Juan Wang \\ School of Cybersecurity, Chengdu University of Information Technology \\ *Corresponding author. Email: wangzuli@cuit.edu.cn

\begin{abstract}
According to the current demand for information security talents, combined with the exploration practice in this major for more than 10 years, the paper puts forward the information security professional talent training mode -"production and learning cooperation, four in one" and the practical training mode-"competition-learning interaction" is adopted. Combined with the results, the effect of the reform is fully proved, and the future work is prospected.
\end{abstract}

Keywords: Information Security, Specialty Training Mode, Talent Training, Practical Teaching.

\section{BACKGROUND}

With the spirit of "We should have high quality network security and information talent team" pointed out by the general secretary Mr.Xi in 2014, the demand for network security talents has increased rapidly. In the face of the problems of "the shortage of talents, low ability and unreasonable structure of network security talents in China" The key choice of building a network power is to speed up the training of information security, especially network security talents and strengthen the construction of network security professional education system.

The major of Information Security in our school originated from the direction of Information Security in Computer Science and Technology in 2003.It was approved as the Information Security, and became the Pilot Specialty of Sichuan Excellent Engineer Education and Training Program in 2013.This major belongs to the First-class Discipline of Cybersecurity In 2017, the discipline of Cybersecurity in our university was listed in the first batch of Double First-class Construction Disciplines in Sichuan Province in 2018.The Provincial Application Demonstration Major was successfully approved, and was selected as the First-class Undergraduate Major Construction Site in Sichuan Province in 2019.After years of practical exploration, deepening the professional reform, we gradually established the talent training target suitable for the school's own characteristics, and found out the training mode of Applied Information Security Talents in line with its own positioning.

\section{TALENT TRAINING SYSTEM OF "COOPERATION OF PRODUCTION AND LEARNING, FOUR IN ONE"}

\subsection{The Construction of Talent Training System with Students as the Center, Continuous Improvement and Output Oriented}

From 2016, the major began to carry out the reform of the talent training system for output; taking the engineering education professional certification as an opportunity, taking students as the centre and output as the guidance, the system of talent training oriented to output has been established. Through students, teachers, managers, experts and employers, the problems in the teaching process are monitored and evaluated by means of teaching inspection, expert evaluation, graduate feedback, student discussion, teaching evaluation, teaching research activities, teaching analysis and others. The purpose of talent training should be reconstructed, and the application-oriented senior professionals who can engage in product research and development and safety testing in information security related industries and in the fields of government, military industry, finance, education and energy can be trained. The course system and content shall be scientifically and reasonably planned, teaching methods shall be adjusted continuously to strengthen the cultivation of engineering practical ability. 


\subsection{Reconstruct the Curriculum Group Structure System in the Major of Information Security Based on the Concept of Engineering Education and the Requirements of "New Engineering" Training in Colleges and Universities}

Based on the concept of engineering education and the requirements of "New Engineering", we reconstruct the curriculum group structure system in the major of information security, carry out the integrated design of theoretical and practical curriculum groups, and systematically cultivate students the engineering awareness and engineering ability. The course system of engineering ability and innovation consciousness are established by curriculum platform and practice platform step-by-step. We will strengthen the reform of the curriculum, vigorously promote the construction of advanced information means of curriculum, and promote the construction of "golden course" in major based on the sharing of online and offline high-quality resources and the application of advanced teaching methods.

\subsection{Establish the Practical Teaching System - "Four in One"}

Practical ability is the key in the major training. The specialty establishes the practical concept of production, learning and research cooperation, which is guided by enterprise demand, student-centred, in school tutor and enterprise tutor. Through joint well-known enterprises, establish practice sites outside the school, guide students to understand the frontier technology, contact with front-line engineers, close, broaden their horizons and thinking, and train network security talents with innovative thinking.

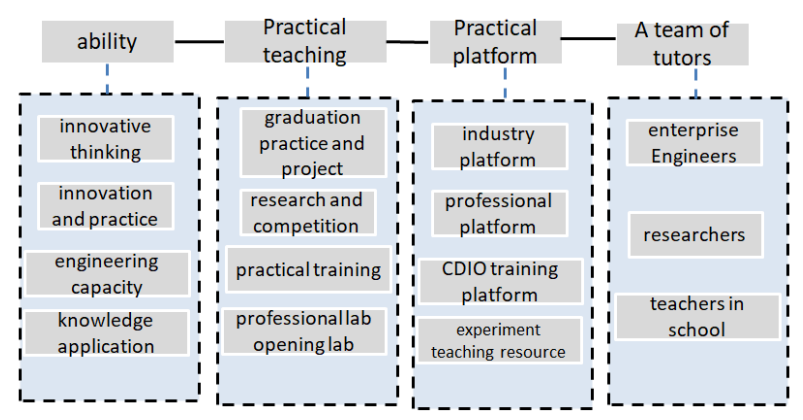

Figure 1 Practical teaching system of production and learning coordination -"four in one"

The major also builds a integration of "experimental teaching, professional practice (practical training), scientific research training (scientific research feedback teaching), industrial practice" based on the course experiment of engineering basic course and professional basic course, taking the engineering practice course of information security as the training carrier of engineering practice ability, and by virtue of students innovation and entrepreneurship projects and discipline competition and other student practice activities. The "industrial practice" takes the whole process of project development as the main line to cultivate student's ability to solve complex engineering problems and scientific research innovation ability.

\subsection{Strengthen the Construction of Professional Teaching Quality Assurance System}

(1) Building teaching quality standard system

According to the school orientation and the general goal of talent training, on the base of process assessment, the major takes system in the course assessment with strong practicality and long duration, such as curriculum design, engineering practice, professional practice and graduation practice, and has issued a number of supporting rules and regulations and management methods, standardizing teaching management, and establishing the objectives, organization, guarantee, management. The teaching quality assurance and monitoring system composed of five parts of theory and evaluation feedback.

Taking the professional engineering certification as an opportunity, we establish a complete evaluation mechanism of the degree of graduation requirements and the achievement of training objectives. Requirements achieved by combination of subjective and objective.

The evaluation of the achievement of curriculum objectives covers the whole process of curriculum implementation, and the non-examination parts and the final test paper results form a comprehensive evaluation.

\section{(2) Build quality assurance team}

The major has established the leading organization, management organization, executive organization and supervision organization of teaching quality assurance system, and clarified their respective responsibilities. At the same time, a teaching management team with both specialized and combined and cooperative division of labor was established. The teaching supervision organization mainly composed of retired teachers was selected to achieve the full coverage of students; teaching information staff. The construction of teaching operation management team with perfect organization and clear responsibilities has realized the effective management of the whole process of talent training, and ensures the implementation of teaching management system in the teaching operation process. Through the collection and analysis of teaching operation status data, the effective monitoring and evaluation of the teaching quality assurance work results of this major are realized, 
which provides the basis for further improvement of management and quality improvement.

(3) Strengthen process monitoring and improve quality assurance mechanism

Experts from both inside and outside of the school were invited to analyse the training plan and resource conditions of the University, and then the comprehensive revision of the talent training plan was organized. Hold teaching work meetings regularly to strengthen daily teaching inspection and special inspection. Organize the mid-term teaching inspection, and carry out special inspection on the teaching work operation, teaching management, teaching style, teaching plan implementation, graduation thesis (design), curriculum examination, experimental training and other parts in each semester through self-inspection or evaluation, so as to realize the full coverage of the monitoring and evaluation of teaching operation process.

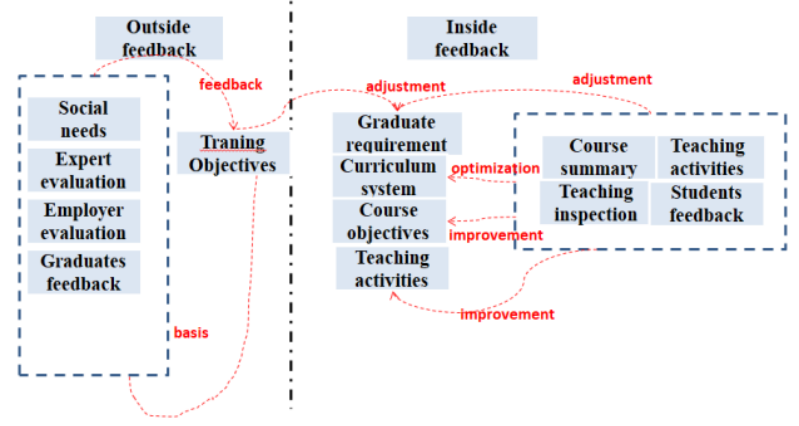

Figure 2 Quality assurance mechanism

\section{THE TRAINING MODE OF PRACTICAL ABILITY OF "COMPETITION-LEARNING INTERACTION"}

Since 2015, the professional teacher tutor system has been implemented. After students enter the school, they are equipped with professional guidance teachers. They will guide the questions, personal development planning, professional knowledge and application prospects, and the selection and implementation of engineering practice projects. With the support of professional teachers, professional students have successively established a number of famous student science and technology associations such as "syclover group", "Dodge safety group" and "contradiction laboratory". Encourage students to participate in various national, provincial and industry information security competitions and innovative and entrepreneurial projects for college students, "practice by competition" and "promote learning by competition". While strengthening students' practical ability, we should find the weak points in teaching through competitions, and constantly improve and promote teaching.

\section{RESULTS}

Since the comprehensive reform of specialty, good results have been achieved.

(1) In recent years, we have won 4 provincial teaching achievement awards in teaching reform, 20 projects have been set up for teaching reform at provincial and ministerial level, 5 excellent courses at school level have been built, 32 teachers have received teaching awards at all levels, and more than 20 teaching reform papers have been published.

(2) In terms of teaching conditions and practice platform construction, we have established more than 20 training practice bases outside the school, including 360 enterprises, China network safety company, Beijing Xipu Sunshine Technology Co. Ltd., and formed the information security laboratory (basic course practice of information security), innovation laboratory (innovation ability practice based on competition and big innovation projects), in school / outside school practice base (the practice of information security and integrity engineering ability in cooperation with enterprises) is a progressive platform for innovation practice training.

(3) Student studies:

(3.1) Have a number of well-known student science and technology associations in China. In the past three years, students have won 22 projects of innovation and entrepreneurship training programs for college students at or above the provincial level ( 8 at the national level and 14 at the provincial level), published 33 academic papers, and won more than 50 awards in information security competitions, with nearly 200 winners.

(3.2) The enrolment rate of graduates has increased year by year, mainly including the well-known universities such as University of Electronic Science and Technology of China and Sichuan University.

(3.3) The employment rate of graduates have steadily increased. The employment rate of graduates is about $90 \%$.

(3.4) The experimental class in the major of Information Security has been set up for more than 10 years, and has trained nearly 500 graduates for the security department, public security and major security companies, and $100 \%$ of them have achieved counterpart employment, and have been widely praised by employers.

(4) Through a research company, the objective survey and evaluation of 2020 graduates of the major have been conducted. According to the survey results, the employment professional relevance of 2020 graduates is $92.98 \%$.The students satisfaction with teaching is higher than $95 \%$ for three consecutive years, the annual income of graduates is 89000 yuan, and the recommendation degree of alumni is $100 \%$.After 
graduation, some graduates will go to Tencent, Baidu, 360, Ali and other well-known enterprises to carry out information security detection and development work, or enter the party and government, military industry, finance, education, energy and other industries to engage in relevant work.

\section{NEXT WORK}

(1) Deepen the construction of talent training system of "cooperation between industry and learning, four in one", and promote the deep integration of science and education and production and education

Cooperate with industry companies in depth, introduce enterprise tutors and dispatched teachers to practice in enterprises. In the ordinary course practice, engineering practice, graduation practice and other processes, the tutors in the school of enterprise tutors will guide and receive feedback together; build up the sharing platform of practice teaching such as innovation laboratory and practice training base to make students innovate and start up daily.

Enterprises participate in professional construction, participate in the formulation of teaching syllabus, optimize the training plan, and comprehensively deepen the cooperation between school and enterprise and school. We will vigorously promote the integration of science and education, realize the transformation of scientific research results into teaching resources, and help to improve the quality of talent training.

(2) Continuously promote professional engineering certification and improve quality assurance system

Taking engineering certification as an opportunity, we should actively promote professional certification. According to the needs of engineering education professional certification, the system of evaluation of the achievement of curriculum objectives and quality feedback of talent training should be improved.

(3) Take science and technology association and science and technology competition as the medium, stimulate innovative thinking and train innovative advanced engineering application talents

We will continue to promote the construction of student's science and Technology Association, such as "Syclover" and "Dodge", encourage students to participate in teacher research and participate in various kinds of science and technology competitions. The platform for Sichuan University of information security technology competition, which has been permanently settled in our university, can promote multi-party communication and achieve the goal of multi-party benign interaction. Finally, a set of cooperative mechanism of talent training quality can be realized by taking extracurricular scientific and technological activities as carrier, interest as the traction, and participating in all parties.

(4) Continue to explore the cultivation of top- talents

Based on the construction of experimental class of information security, we will continue to explore the top application talent training mode, including curriculum system, practice, school enterprise cooperation, innovative thinking training, etc., to provide theoretical and practical basis for the creation of elite talents.

\section{CONCLUSION}

At present, with the construction of "Digital China" and "safe China", it provides a great opportunity for the cultivation of information security talents, but also puts forward a severe challenge. Colleges and universities should combine their own characteristics, widely share experiences, and scientifically build China's information security education system, which is the key to realize the strategic goal of network power.

\section{REFERENCES}

[1] Liu Gang, Liu Lin. Information Security Professional Education System in Russia: Construction and Enlightenment, Journal of Intelligence, 2020.8. DOI: https://kns.cnki.net/kcms/detail/61.1167.G3.20200 731.1523.016.html

[2] Cui jixin, Chu rongzhen. Thoughts on the training mode of information security talents in Colleges and Universities, Education and Teaching Forum, 2018. 7: 223-224.

[3] Li fei, Wu chunwang, Wang juan, Wang zuli, Cooperation of production and learning to build a "four in one" information security personnel training system, Ability and Wisdom, 2019. Vol(18): 166-167.

[4] Wang Xiao mei, Construction of the Innovational and Practical Education System of the Laboratory of the Major of Information Security, Research and Exploration in Laboratory, 2016.No5 Vol(35):174177.

[5] Lai Ying-xu, Evaluation of Engineering Ability of Information Security Undergraduates, Research and Exploration in Laboratory, 2013.No5 Vol(32):150-154.

[6] Jianfeng Gu. 2018. The Research of Higher Education Administration in the Education of Wisdom. Chinese Adult Education, 2018, Vol18: 55-57. 